$15^{\text {th }}$ International Conference on

AEROSPACE SCIENCES \& AVIATION TECHNOLOGY,

$\boldsymbol{A S A T}$ - 15 - May 28 - 30, 2013, Email: asat@ mtc.edu.eg,

Military Technical College, Kobry Elkobbah, Cairo, Egypt,

Tel: +(202) 24025292 -24036138, Fax: +(202) 22621908

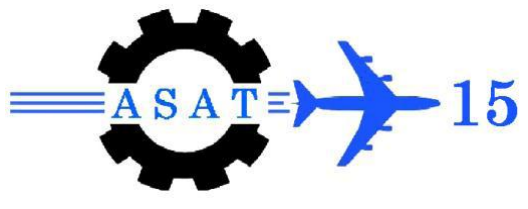

\title{
Enhancement of Ballistic Resistance of Body Armors
}

\author{
\{A.I. Fayed*, M. Abdel Fattah ${ }^{\dagger}$, A.M. $\left.\operatorname{Riad}^{\ddagger}\right\}^{\S}$
}

\begin{abstract}
Body armors must protect the human body from the ballistic penetration of small arms projectiles and to reduce the blunt trauma or the back face signature caused. Blunt trauma can cause severe injuries to vital organs of the body such as heart, liver, lungs kidneys, etc. The design of ballistic-resistant armor requires identification of the threat, selecting a material or combination of materials that resist such a threat, and determining the number of layers of material necessary to prevent both penetration and blunt trauma injury. The final weights of such armors represent an important factor when selecting the materials used for constructing them. Therefore, the main goal is concerned with the design of lightest possible unit that achieves the desired protection and provides comfort and not restricting movement.
\end{abstract}

In this paper, the ballistic resistances as well as Back Face Signature (BFS) of two ballistic panels have been examined, one was normal panel, and the other was treated by applying thin layer of a flexible polymeric material on its back face. An experimental program has been conducted to study the normal penetration of a $9 \times 19 \mathrm{~mm}$ projectile into each of the two body armor panels. The program is concerned with the determination of the back face signature depth and its maximum diameter.

Autodyn-3D hydro-code was used for simulating the projectile penetration process into the prepared ballistic panels [1]. The input data of projectile and body armors used in experimental program were fed into the code. The numerical simulation results were compared with the corresponding experimental measurements.

Keywords: Body armor, ballistic panel, back face signature, penetration, ballistic tests, and numerical simulation.

\section{Introduction}

Nowadays, ballistic impact simulation is used as a way to understand damage mechanisms and mechanics of laminated and composites structures. With the development of computer hardware and decades of research in these techniques, computational simulations have become both feasible and low cost effective to reduce the physical experimentations and also to optimize the parameters involved. The numerical results should be used with precaution and must always be validated by experimental tests. AUTODYN is an example of software package designed to solve numerically a lot of non-linear dynamic problems [2].

\footnotetext{
alhfayed@yahoo.com

gamhoudy@yahoo.com

$\$$, ahmed riad10@ hotmail.com

$\S \quad$ Egyptian Armed Forces. Egypt.
} 
$\mathrm{Wu}$ et al. [3] were performed their experimental tests to determine the ballistic limits of unidirectional and woven E-glass/epoxy laminates, respectively. The thicknesses were 2.8 $\mathrm{mm}$ for unidirectional (UD) laminates and $2.9 \mathrm{~mm}$ for woven E-glass/epoxy laminates. They used hemispherical tip ended projectiles. Laser Doppler Anemometry (LDA) was used to measure the velocity profile of the projectile which was in turn used to get the resisting force history of the laminate. For the UD at velocities near the ballistic limit, they observed that the fiber bundles were sheared off by the projectile. In addition, they found that the peak of resisting force occurred at the ballistic limit, such thing was not observed for impact on woven composites. They also noticed that the ballistic limit was high for UD which was opposite to the popular belief.

Bohong $\mathrm{Gu}$ [4] introduced a finite element model (FEM) to simulate the entire process of multi-layered fabric target perforated by conically cylindrical steel projectile on the basis of the description of the actual structure of fabric considering crimps of warp and weft yarns. The original idea of his work was based on representing the actual structure of multi-layered fabric target and the constitutive equations of yarns at a high strain rate in the finite element model. He meshed the projectile and yarns in the fabric with eight-node hexahedron element. The available finite element code Ls-Dyna was incorporated with the constitutive equations of filament yarns at high strain rate to simulate the ballistic impact response. For the multilayered fabric targets, he found that the maximum relative error between the predicted residual velocity and the corresponding measurement was $6.4 \%$.

Cunniff [5] briefly reviewed prior work on fabric-based armor system. He discussed the event occurring during the ballistic impact of woven fabric body armor materials to correlate the single yarn impact mechanics with the fabric impact mechanics. In addition, he discussed the consequence of assembling yarns into single-ply fabric structures. He used the striking and residual velocity data, collected for single-ply fabric systems of Spectra, Kevlar 29, and nylon with different yarn deniers and weave types, to establish the response of spaced armor systems. He determined the system effects of assembling fabric plies into body armor systems by comparing the response of spaced armor systems to actual multiple-ply systems. He found that there were a pronounced decrease in energy absorption capacity for the spectra and nylon multiple-ply systems; this was attributed to the increase of transverse stresses and the possible interference of the deflection characteristics of fabric plies.

Tan and Ching [6] introduced a numerical model of woven fabric considering the orthotropic properties of the fabric, the viscoelastic nature of the yarns, the crimping of the yarns, and the sliding contact between yarns and yarn breakage using an assembly of viscoelastic bar elements. Their model has been implemented using a commercial finite element code (LsDyna). They performed ballistic tests on woven aramid fabric specimens (Twaron CT716) prior to the numerical simulations. The fabric specimens had dimensions of $120 \mathrm{mmX} 120 \mathrm{~mm}$, and the projectile was a steel sphere with a diameter of $12 \mathrm{~mm}$ and a mass of $7 \mathrm{~g}$. Their projectiles were propelled normally onto the centre of the fabric targets by a high pressure gas gun, with impact velocities ranging from 80 to $520 \mathrm{~m} / \mathrm{s}$. Two different sets of simulations with different boundary conditions were done in this study. In the first set, the fabric targets were fully clamped on all four edges during the ballistic impact tests. In the second set, the fabric targets were fully clamped on two opposite edges only. The measured ballistic limit of the used fabric target was about $110 \mathrm{~m} / \mathrm{s}$. The numerical model predicted a slightly more conservative ballistic limit of $105 \mathrm{~m} / \mathrm{s}$. In general, their numerical results were in good agreement with the corresponding experimental measurements. 
For illustrating the ballistic performance of body armor, Figure 1 presents the probability of success of certain body armor when defeating a certain projectile with different impact velocities. The illustrated figure includes three main zones. The first presents the ballistic stability zone (from 0 to V0), in which the tested body armor can stop all falling projectiles with defined impact velocity in compliance certificate of tested body armor. In the second zone, zone of mixed results (from V0 to V1); the tested body armor may defeat the falling projectile according to the tolerances in impact velocity around the value of limit velocity of the armor. In the third zone, zone of ballistic instability (velocity above V1), all projectiles can easily perforate the tested armor. The standards for bullet-proof vests are always working in the first zone. After five years working, performance of most body armors starts to move towards the second zone, zone of mixed results, which means the reduction in ballistic limit of tested body armors. The drop in ballistic resistance of body armors may always happen due to working condition of the armors such as environmental conditions of storage, direct exposure to sun light and humidity. Reduction in limit velocity may also notice by increasing the signature of impacting projectile on back face of body armor, i.e. blunt trauma. The maximum value of trauma depth must not exceed $44 \mathrm{~mm}$ according to NIJ standard.

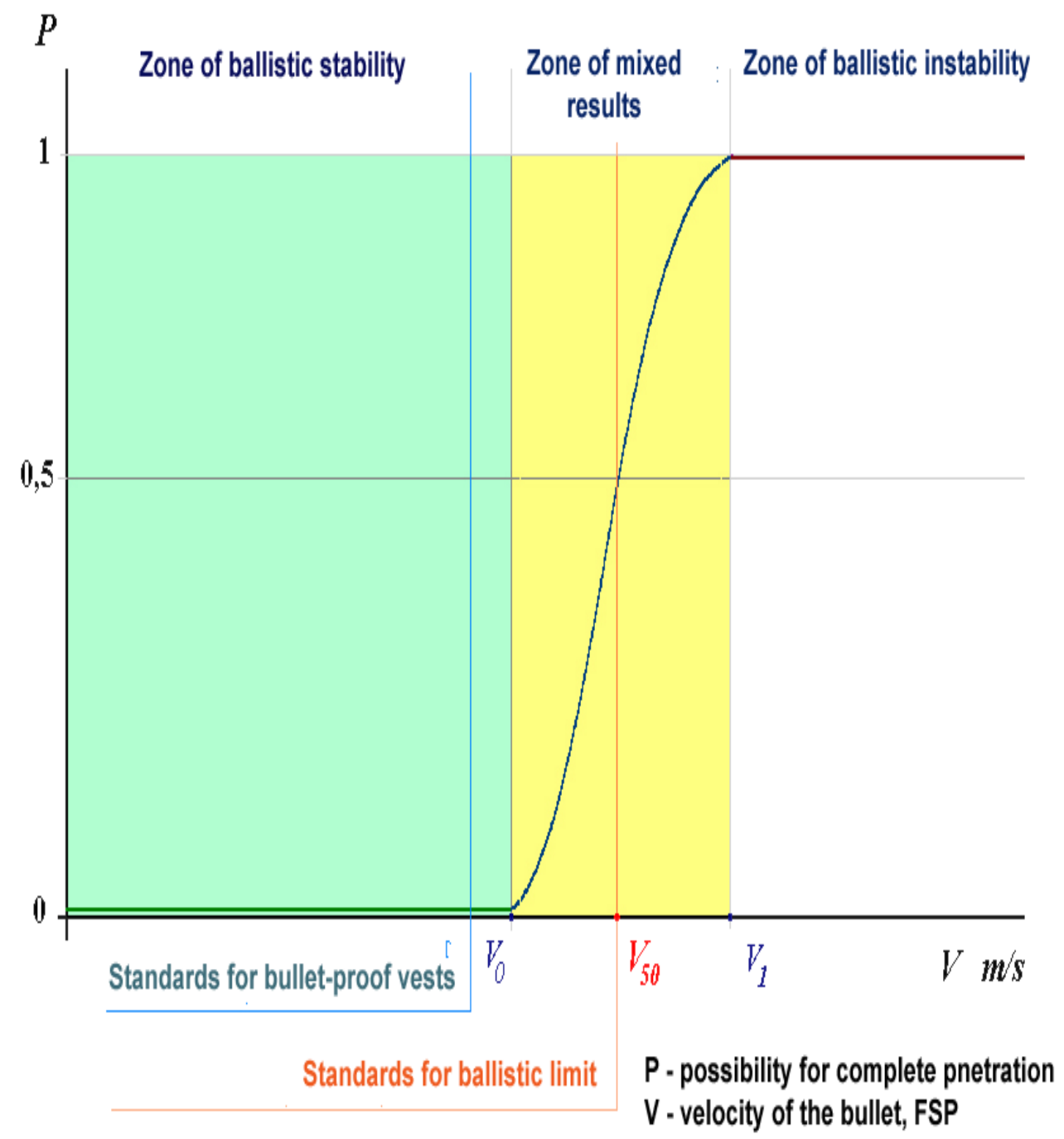

Fig. 1 Ballistic zones for tested body armor 
The main objective of the present work is to reduce the back face signature of the body armors in order to improve their ballistic performance. Therefore, an experimental program has been conducted to study the penetration of a small caliber projectile into different body armors [7]. In addition, the perforation process of the small caliber projectile into each body armor has been simulated using Autodyn-2D hydrocode. The input data of the experimental program were fed into the code. The obtained experimental measurements are compared with the corresponding predictions of the Autodyn-3D hydro-code.

\section{Experimental Program}

An experimental program has been conducted to study the penetration of a small caliber projectile into two different panels of body armors. The first panel consisted of twenty six layers of aramid and designated by A-26, whereas the second consisted of twenty four layers of aramid and latest two layers of aramid/line-X as a backing and designated by A/L-26. The two panels were tested ballistically using a $9 \times 19 \mathrm{~mm}$ normal projectile (lead core). The experimental facilities of the Armed Forces Technical Research Center (AFTRC) shooting range were used to perform these tests. In general, the scheme of the experimental work included the following activities: (a) Material choice and preparation of body armor, (b) Ballistic tests and measurements, (c) Post-firing examinations.

\section{Material Choice and Preparation of Body Armor}

LINE-X XS-350 is a product of AAT and American Advanced Technology Company. This product consists of multi-components, spray-in-place flexible $100 \%$ solid Polyurea /Polyurethane system. It is prepared for processing through LINE-X dispensing equipment. It has fast cure for service at ambient temperature after 24 hours. In addition, it has low density and relatively high abrasion resistance, high impact strength, high tensile strength, high resistance to severe weather conditions, and high elongation percent. In the present work, a ballistic panel of (26 layers of aramid fibre) is prepared by spraying a thin layer of LINE-X to the back of its latest two layers. The method of preparation a flexible composite material for the purpose of absorption of impact energy is illustrated by Fayed et al. [8].

\section{Ballistic Tests and Measurements}

The ballistic experiments were performed in the ballistic shooting range of AFTRC, which had provisions for the measurement of projectile impact velocity, the back-face signature depth and the corresponding diameter of the back-face signature according to NIJ standard [9]. As shown in Fig. 2, the ballistic set-up mainly consists of: ballistic rifle having a caliber of $9 \mathrm{~mm}$, velocity measurement device, plasticine backing material, and target mount. The ballistic tests were performed on the two prepared panels, one without LINE-X and the other with LINE-X as explained before.

\section{Post-Firing Examinations}

Both the original ballistic panel and that prepared with LINE-X were examined after hitting each of them by six shots according to NIJ standard to determine if perforation took place or not. The backface signature and the corresponding diameter will be measured. If the BFS depth due to any shot is greater than $44 \mathrm{~mm}$, the whole body armor is considered to be failed. In addition, the backing material must be prepared and calibrated according to NIJ standard before each subsequent test [9]. 


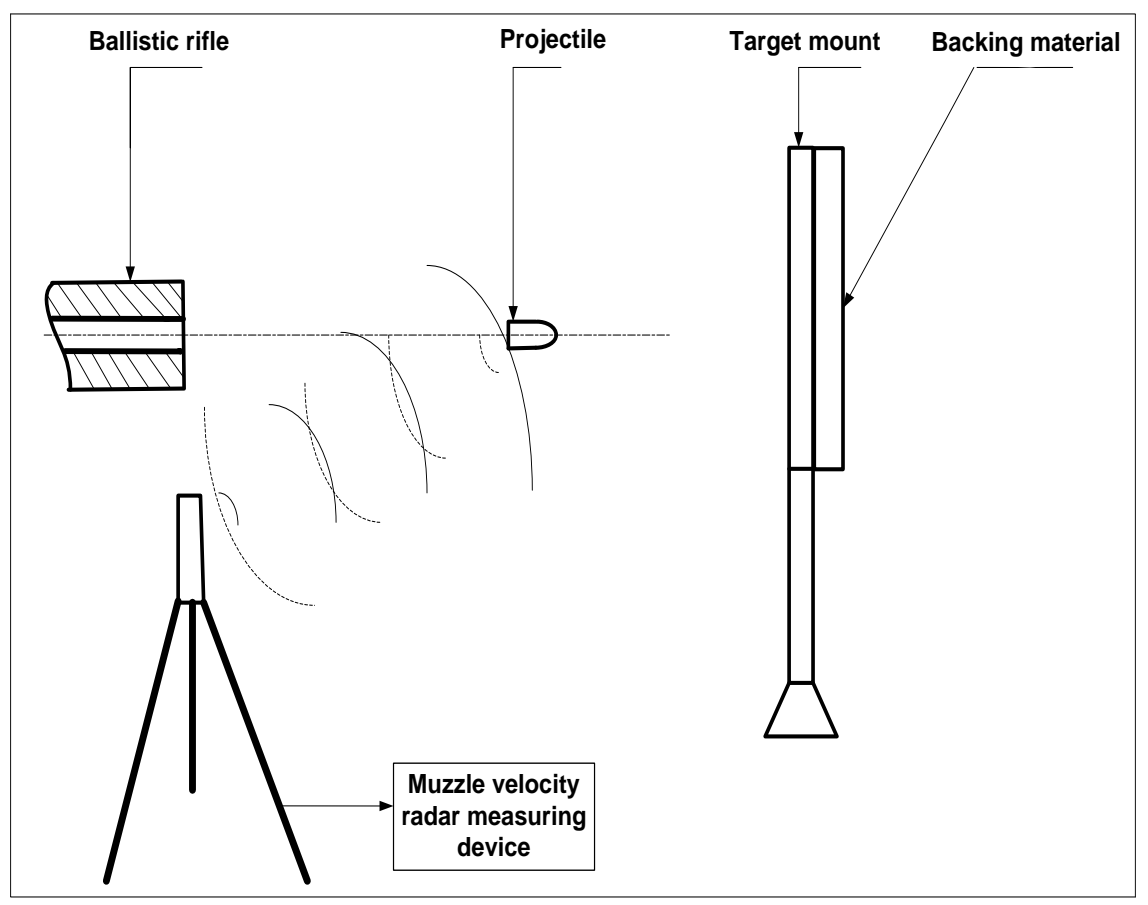

Fig. 2 Scheme of ballistic set-up

\section{Numerical Simulation}

In the following, the perforation process of the original ballistic panel and that prepared by LIEX-X were simulated using Autodyn-3D hydrocode. Figure 3 shows the starting cycle of the simulated penetration process into Autodyn-3D hydrocode. The input data fed to the code are listed in Tables 1 and 2. These data for armor and projectile materials as well as the projectile impact velocity are that measured in the experimental program. The numerical simulation results will be compared with the experimental measurements due to the penetration of a $9 \mathrm{~mm}$ projectile into each panel.

\section{Results and Discussions}

In the following, the present results are divided into: (i) ballistic firing test results, (ii) postfiring examinations of each tested panel, and (iii) comparison between the ballistic measurements and the corresponding numerical simulation results for each panel.

\section{Ballistic Firing Test Results}

In the following, both the depth of the backface signature and the corresponding diameter on the backing material are selected to enhance the ballistic panel resistance to penetration. Each panel was impacted by six projectiles; no perforation occurred for any of them. Table 3 summarizes the results of firing tests performed for the two panels. For each test, the measured projectile impact velocity, the backface signature dept and its corresponding diameter at the backing of body armor are listed in the table. 


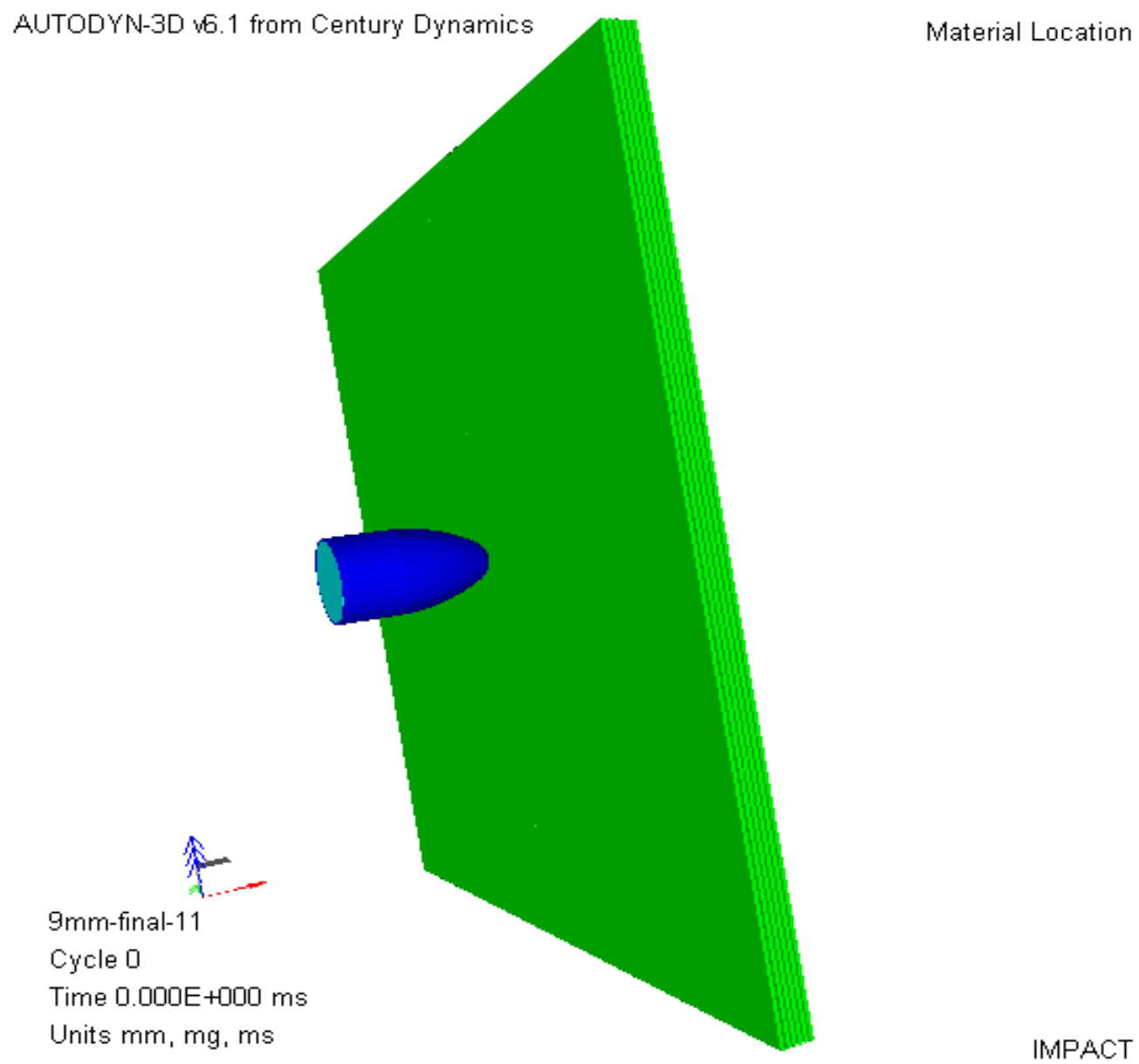

Fig. 3 3D modeling of projectile and target plate.

Table 1 Input data to the code for the used projectile.

\begin{tabular}{|c|c|c|}
\hline \multirow{2}{*}{ Parameter } & \multicolumn{2}{|c|}{ Projectile material } \\
\hline & Lead & Copper \\
\hline Projectile designation & \multicolumn{2}{|c|}{ P-LC } \\
\hline Reference density, (kg/m3) & 11.34 & 8.45 \\
\hline Equation of state & \multicolumn{2}{|c|}{ linear } \\
\hline Strength model & \multicolumn{2}{|c|}{ Von-Mises } \\
\hline Reference temperature, $(\mathrm{K})$ & \multicolumn{2}{|c|}{300} \\
\hline Outer diameter of copper jacket, $(\mathrm{mm})$ & \multicolumn{2}{|c|}{9.0} \\
\hline Inner diameter of copper jacket, $(\mathrm{mm})$ & \multicolumn{2}{|c|}{8.5} \\
\hline Outer diameter of lead jacket, $(\mathrm{mm})$ & \multicolumn{2}{|c|}{8.5} \\
\hline Yield stress, $(\mathrm{kPa})$ & $3.00 \mathrm{E} 4$ & 7.00E4 \\
\hline Shear modulus, $(\mathrm{kPa})$ & $1.113 \mathrm{E} 7$ & $4.8 \mathrm{E} 7$ \\
\hline Bulk modulus, $(\mathrm{kPa})$ & $4.6 \mathrm{E} 7$ & $1.4 \mathrm{E} 8$ \\
\hline Erosion strain & \multicolumn{2}{|c|}{1.00} \\
\hline
\end{tabular}


Table 2 Input data to the code for the ballistic panels.

\begin{tabular}{l|c|c}
\hline \multirow{2}{*}{ Parameter } & \multicolumn{2}{|c}{ Composite plate } \\
\cline { 2 - 3 } Reference density (kg/m3) & Aramid (A-26) & Aramid/line-x (A/L-26) \\
\hline Equation of state & \multicolumn{2}{|c}{ Orthotropic } \\
\hline Strength model & \multicolumn{2}{|c}{ Elastic } \\
Reference temperature (K) & 300 & 300 \\
\hline Composite thickness (mm) & 0.35 & 1.35 \\
\hline Plate area, (mm2) & $150 \times 150$ & $130 \times 150$ \\
\hline Tensile failure strain (\%) & 3.3 & $5.9 \mathrm{E} 5$ \\
\hline Shear Modulus, (kPa) & $2.9 \mathrm{E} 6$ & $62.00 \mathrm{E} 6$ \\
\hline Young's Modulus, (kPa) & $80.00 \mathrm{E} 6$ & 1.00 \\
\hline Erosion strain & 1.00 & \multicolumn{2}{|c}{} \\
\hline \hline
\end{tabular}

According to NIJ standard, the acceptance criterion for partial penetration and backface signature (BFS) compliance will be as follows:

a) No perforation through the body armor, either by the bullet or by any fragment of the bullet or armor.

b) No measured BFS depression depth greater than $44 \mathrm{~mm}$.

The ballistic measurements prove that the two tested panels realize the acceptance criterion for partial penetration and back-face signature. In addition, the use of two layers of A/L-26 at the back of body armor decreases the backface signature by average value about $7.2 \mathrm{~mm}$ compared with the corresponding average value of A-26 panel. (i.e. reducing BFS by about $35 \%$ compared with A-26 panel).

\section{Post-Firing Examinations of Each Tested Panel}

Post firing examinations were mainly performed for each tested panel. Figures 4 and 5 show the back-faces of A-26 and A/L-26, in order, after impacting each of them by six $9 \mathrm{~mm}$ projectiles. It is also seen that the signature of plasticine on (A-26) armor is greater than that of (A/L-26) armor which means that the back-face signature in case of (A-26) armor is greater than that of $(\mathrm{A} / \mathrm{L}-26)$ armor. 


\section{Comparison between Ballistic Measurements and the Corresponding Numerical Simulation Results}

The Autodyn-3D hydrocode was used to simulate the penetration process of each tested panel. The values of the backface signature depth $(\mathrm{z})$ and the corresponding diameters $(\mathrm{dt}=2$ rt) due to the impact of each panel by a $9 \mathrm{~mm}$ projectile are determined. The code was fed with impact velocities of $380 \mathrm{~m} / \mathrm{s}$ for A-26 panel and $378.3 \mathrm{~m} / \mathrm{s}$ for A/L-26 panel. These velocities represent the average of measured impact velocities forr each panel. Table 4 lists the average of the measured backface signature and the average of their corresponding diameters for each panel. The corresponding predictions of Autodyn-3D hydrocode are listed in the same table.

Table 3 Ballistic test results for the prepared body armors

\begin{tabular}{|c|c|c|c|c|c|c|}
\hline $\begin{array}{c}\text { Target } \\
\text { designation }\end{array}$ & $\begin{array}{l}\text { Measured } \\
\text { impact } \\
\text { velocity, } \\
\text { Vi }[\mathrm{m} / \mathrm{s}]\end{array}$ & $\begin{array}{c}\text { Average } \\
\text { impact } \\
\text { velocity, } \\
\text { (Vi )ave } \\
{[\mathrm{m} / \mathrm{s}]}\end{array}$ & $\begin{array}{c}\text { Measured } \\
\text { depth of } \\
\text { BFS, } \\
\mathrm{z} \\
{[\mathrm{mm}]}\end{array}$ & $\begin{array}{c}\text { Average } \\
\text { depth of } \\
\text { BFS, } \\
\text { zave } \\
\text { [mm] }\end{array}$ & $\begin{array}{c}\text { Measured } \\
\text { diameter, } \\
d_{t} \\
{[\mathrm{~mm}]}\end{array}$ & $\begin{array}{c}\text { Average } \\
\text { diameter, } \\
\mathrm{dt} \text { ave } \\
{[\mathrm{mm}]}\end{array}$ \\
\hline \multirow{6}{*}{ A-26 } & 378 & \multirow{6}{*}{380} & 25 & \multirow{6}{*}{20.8} & 67 & \multirow{6}{*}{74} \\
\hline & 385 & & 21 & & 85 & \\
\hline & 374 & & 24 & & 78 & \\
\hline & 381 & & 17 & & 73 & \\
\hline & 386 & & 20 & & 68 & \\
\hline & 376 & & 18 & & 73 & \\
\hline \multirow{6}{*}{ A/L-26 } & 380 & \multirow{6}{*}{378} & 16 & \multirow{6}{*}{13.6} & 58 & \multirow{6}{*}{51.8} \\
\hline & 379 & & 17 & & 50 & \\
\hline & 372 & & 13 & & 58 & \\
\hline & 385 & & 15 & & 52 & \\
\hline & 397 & & 11 & & 45 & \\
\hline & 375 & & 10 & & 48 & \\
\hline
\end{tabular}

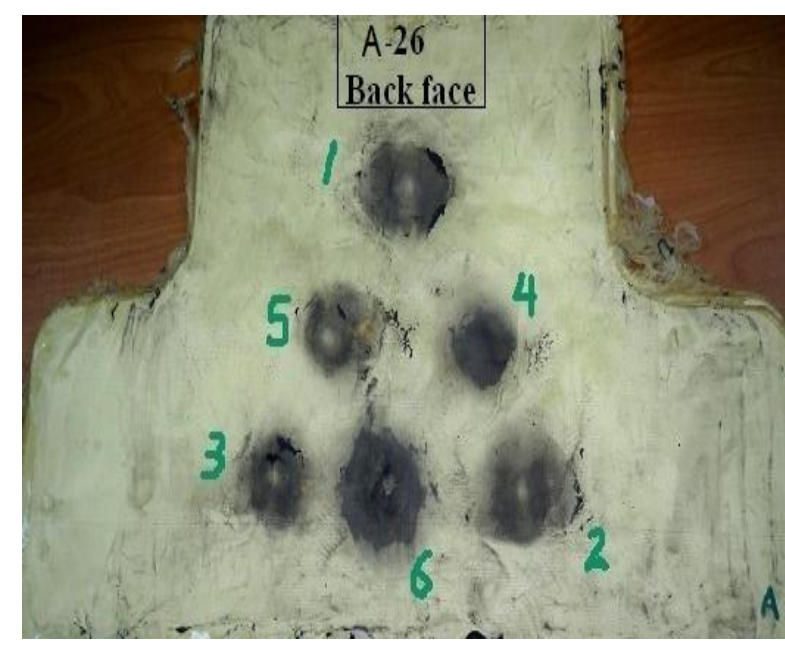

Fig. 4 (A-26) body armor impacted by $9 \mathrm{~mm}$ projectiles.

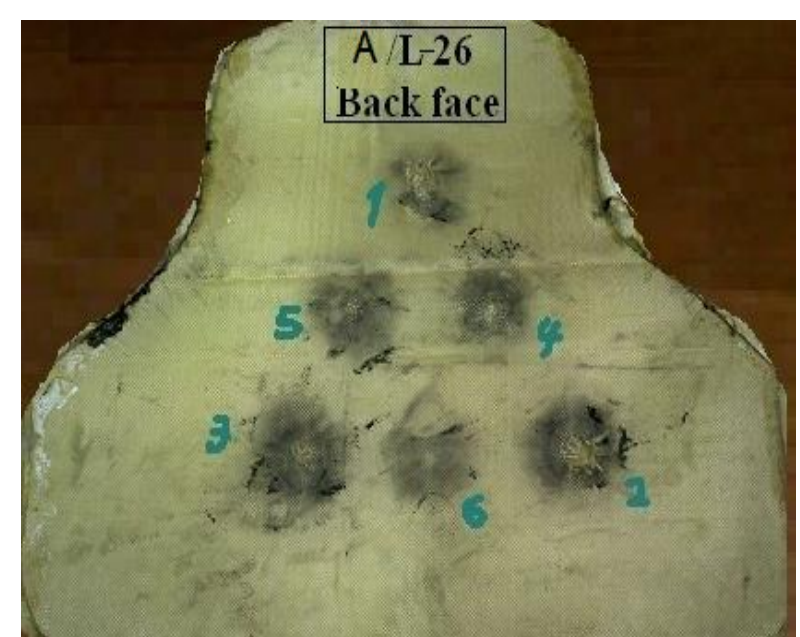

Fig. 5 (A/L-26) Body armor impacted by $9 \mathrm{~mm}$ projectiles. 
Table 4 Average of the measured depths of BFS for A-26 and A/L-26 armors and the corresponding predictions by Autodyn-3D code.

\begin{tabular}{c|c|c|c|c|c}
\hline \hline $\begin{array}{c}\text { Body } \\
\text { armor } \\
\text { design }\end{array}$ & $\begin{array}{c}\text { Average } \\
\text { measured } \\
\text { impact } \\
\text { velocity, } \\
(\mathrm{Vi}) \mathrm{ave} \\
{[\mathrm{m} / \mathrm{s}]}\end{array}$ & $\begin{array}{c}\text { Average } \\
\text { measured } \\
\text { depth of } \\
\text { BFS, } \\
(\mathrm{z}) \mathrm{ave} \\
{[\mathrm{mm}]}\end{array}$ & $\begin{array}{c}\text { Predicted } \\
\text { depth of } \\
\text { BFS, } \\
\mathrm{z} \\
{[\mathrm{mm}]}\end{array}$ & $\begin{array}{c}\text { Average } \\
\text { measured } \\
\text { diameter } \\
\text { of BFS, } \\
(\mathrm{dt}) \mathrm{ave} \\
{[\mathrm{mm}]}\end{array}$ & $\begin{array}{c}\text { Predicted } \\
\text { diameter } \\
\text { of BFS, } \\
(\mathrm{dt}) \\
{[\mathrm{mm}]}\end{array}$ \\
\hline A-26 & 380 & 20.8 & 6.5 & 74 & 70 \\
\hline A/L-26 & 378.3 & 13.6 & 4.1 & 51.8 & 62 \\
\hline \hline
\end{tabular}

It is seen from the Table 4 that the average measured BFS for each panel is less than that allowed by NIJ standard. For A-26 panel, the relative difference between the measured BFS and that of NIJ standard is more than 50\%; this difference increases for A/L-26 panel. However, the average measured diameter of BFS for each tested panel is close to the corresponding prediction, the predicted BFS for each panel is not consistent with the corresponding experimental measurements.

Further numerical work is needed to predict close results to that obtained by experiments. The discrepancies may be attributed to the local effect of the penetration process simulated by the Autodyn-3D code.

\section{Conclusions}

The following points could be drawn out from the present work:

A new body armor configuration has been constructed and tested; this body armor consists of twenty four layers of aramid and two separated layers of aramid/line-X 350 as a backing. Ballistic tests prove the capability of such a new armor to reduce the backface signature by about $35 \%$ compared with that of the body armor without line-X when impacted by a $9 \mathrm{~mm}$ projectile.

The principle of tested panel -Aramid/line-X-can be used as a solution for older one; it will reduce the depth of blunt trauma and its maximum diameter.

Further simulation work using Autodyn-3D code is needed to improve its predictive capabilities concerning with the backface signature of body armors.

\section{References}

[1] Century Dynamics, Inc. AUTODYN "Interactive Non-Linear Dynamic Analysis software" (1997).

[2] A. M. Hamouda and M. S. Hashmi, "Modelling the Impact and Penetration Events of Modern Engineering Materials: Characteristics of Computer Codes and Material Models", J. Materials Processing Technology, Vol. 56, pp. 847-862 (1996).

[3] E. Wu, C. Z. Tsai and Y. C. Chen, "Penetration into Glass/Epoxy Composite Laminates", J. Compite Materials, Vol. 28, pp. 1783-1802 (1994). 
[4] Bohong Gu, "Ballistic Penetration of Conically Cylindrical Steel Projectile into Plainwoven Fabric Target - A Finite Element Simulation", J. Composite Materials, Vol. 38, No. 22 (2004).

[5] P. M. Cunniff, "An Analysis of the System Effects in Woven Fabrics under Ballistic Impact", J. Textile Res., Vol. 62, No.9, pp. 495-509 (1992)

[6] V.B.C. Tan and T. W. Ching, "Computational Simulation of Fabric Armour Subjected to Ballistic Impacts", Int. J. Impact Engng., Vol. 32, pp. 1737-1751 (2006).

[7] M. El-Gamhoudy,"Ballistic Resistance of Laminated Composite Targets", M. Sc. Thesis, Military Technical College (M.T.C.), Cairo, Egypt (2010).

[8] A. I. Fayed, E. E. Elawad, and M. S. Abdelkader "Penetration of Flexible Composite (Kevlar-129/Line-X XS 350)", Proceedings of the 11th Int. Conf. on Aerospace Science \& Aviation Technology, M.T.C., Cairo, May ( 2005).

[9] "Ballistic Resistance of Personal Body Armor", National Institute of Justice, NIJ Standard 0101-04. 